\title{
Engagement in daily life physical activity reduces self-reported symptoms in adolescent concussion
}

\author{
Matthieu P. Boisgontier*, Boris Cheval ${ }^{1}$, Julia Schmidt ${ }^{2, *}$ \\ ${ }^{1}$ Department of Psychology, University of Geneva, Switzerland \\ ${ }^{2}$ Department of Occupational Therapy, University of British Columbia, Vancouver, Canada \\ *Corresponding authors: matthieu.boisgontier@ubc.ca; julia.schmidt@ubc.ca
}

Please cite as: Boisgontier, M.P., Cheval, B., Schmidt, J. (2019). Engagement in daily life physical activity reduces self-reported symptoms in adolescent concussion. SportRxiv. https://doi.org/10.31236/osf.io/nhg6c

All authors have read and approved this version of the manuscript.
The authors can be reached on Twitter @MattBoisgontier @chevalboris @jy_schmidt 


\section{ABSTRACT}

Background: Concussion is a common injury in an adolescent population with up to $20 \%$ experiencing persistent symptoms. Rehabilitation programs that include aerobic exercises can reduce persistent postconcussion symptoms, however it is unclear if daily-life physical activities can also reduce symptoms. Purpose: To investigate whether the level of daily life physical activity reduces postconcussion symptoms in adolescents. Methods: Ten adolescents aged 11-18 years with a concussion self-reported their postconcussion symptoms and level of physical activity at 1, 3, and 6 months after injury. The extent to which physical activity explained postconcussion health was analyzed using linear mixed modeling. Results: Higher levels of daily-life physical activity were associated with fewer somatic and cognitive symptoms, irrespective of age, gender, and time postconcussion. Implications: These findings suggest that daily life physical activity, including engagement in physical education class, sports, or active games, should be encouraged by Occupational Therapists to promote concussion recovery.

Keywords: Mild traumatic brain injury, Pediatrics, Exercise.

\section{INTRODUCTION}

Concussion (i.e., mild traumatic brain injury) is a common injury and a major public health burden, particular in an adolescent population as the developing brain is more vulnerable to injury (Rajabali, Turcotte, Pike, \& Babul, 2016). Rates of mild TBI can only be estimated, as up to $88 \%$ of cases go unreported. However, even reported rates are high: between 2005 to 2009, children and adolescents made more than 1.9 million outpatient visits and 3 million emergency department visits for concussion (Mannix, O’Brien, \& Meehan, 2013).

Symptoms of concussion can include somatic (e.g., headache, dizziness) emotional (e.g., unstable mood, depression), physical (e.g., balance and visual-ocular motor deficits), and cognitive complaints (e.g., inattention, forgetfulness) (Barlow et al., 2010). Most adolescents who sustain a concussion experience no symptoms after the typical 1-month recovery period. However, approximately $20 \%$ experience persistent symptoms, which can negatively impact various occupations such as school, work, and play (Barlow, 2016; Barlow et al., 2010; Iverson, 2005). Specifically, prolonged concussion symptoms and consequent activity limitations can negatively affect emotional control, influence academic and social roles (Valovich McLeod, Wagner, \& Bacon, 2017), and impact self-perception (Sveen, Søberg, \& Østensjø, 2016).

Participation in physical activity has shown to improve health outcomes in multiple brain-related conditions including stroke, Alzheimer's disease, and Parkinson's disease (Cotman, Berchtold, \& Christie, 2007). For example, physical activity accelerates functional rehabilitation and reduces the risk for subsequent cardiovascular events in people with stroke (Billinger et al., 2014). In people with Alzheimer disease (Larson et al., 2006) and Parkinson's disease (Mak, Wong-Yu, Shen, \& Chung, 2017), physical activity delays onset, reduces the risk, and slows functional decline.

In children, adolescents, and adults affected by a concussion, review articles report that aerobic exercise may improve recovery indices of reduced postconcussion symptoms and days off work (Hugentobler et al., 2019; Lal, Kolakowsky-Hayner, Ghajar, \& Balamane, 2018; Silverberg \& Iverson, 2013). Specifically, adolescents who engaged in a rehabilitation program involving physical activity within the first month after concussion experienced reduced symptoms (Chrisman et al., 2017; Grool et al., 2016). Additionally, rehabilitation programs that included structured aerobic physical activity for adolescents with persistent symptoms beyond one-month reduced persistent symptoms (Gagnon, Galli, Friedman, Grilli, \& Iverson, 2009; Gagnon, Grilli, Friedman, \& Iverson, 2016; Imhoff, Fait, Carrier-Toutant, \& Boulard, 2016; Kurowski et al., 2017). 
Despite evidence on the benefit of physical activity on the experience concussion of symptoms, it remains unclear whether engagement in self-directed, everyday life physical activity (e.g., physical education class, engagement in sports, or playing games during spare time), outside of a structured rehabilitation program, is associated with fewer symptoms after 1-month postconcussion. Therefore, the objective of this study was to investigate whether engagement in physical activity during everyday life reduces postconcussion symptoms in an adolescent population.

\section{METHODS}

\section{Design}

This is a cross sectional study. The Clinical Research Ethics Board (University of British Columbia) approved the study procedure (ID H16-01859) in accordance with the principles of the Declaration of Helsinki.

\section{Participants}

Participants were ten adolescents aged $11-18$ years ( 4 females, 6 males) with a recent ( $<1$-month post injury) physician-diagnosed concussion. Participants were recruited through community advertisements and referrals from the BC Children's Hospital emergency department. All participants and parents/guardians provided written informed assent and consent prior to data collection.

\section{Outcomes}

Outcome measures included a measure of concussion symptoms (Health and Behavior Inventory, $\mathrm{HBI}$ ) and measure of physical activity (Physical Activity Questionnaire for Adolescents, PAQ-A). These measures were conducted at 1, 3, and 6 months after concussion injury.

The $\mathrm{HBI}$ (child version) was used to assess postconcussion symptoms, with higher scores indicating poorer health (Ayr, Yeates, Taylor, \& Browne, 2009). The parent version of the HBI was used to control for the parental assessment of the postconcussion symptoms. This assessment consists of 20 items that measure the frequency of common post-concussive symptoms. The HBI has sound psychometric properties with validity in distinguishing MTBI from other injuries (Hajek et al., 2011; Yeates et al., 2010).

The PAQ-A summary score was used to assess daily-life physical activity, with higher scores indicating higher levels of physical activity (Kowalski, Crocker, \& Kowalski, 1997). It is a nine-item, selfreport questionnaire, asking the participant to recall the past seven days of physical activity. It provides a summary physical activity score derived from eight items (does not include the 9th item in the overall score), each scored on a 5-point scale. The PAQ-A was developed to assess general levels of physical activity for high school students approximately 14 to 19 years old.

\section{Statistics}

The extent to which physical activity explained postconcussion health was analyzed using a linear mixed model in the R software. The equation of this model is as follows:

$$
\begin{aligned}
& \text { Postconcussion Symptoms Score }_{i j} \\
& \qquad \begin{array}{l}
=\beta_{0}+\beta_{1} \text { Physical Activity }_{\mathrm{ij}}+\beta_{2} \text { Time Postconcussion }_{\mathrm{j}}+\beta_{3} \text { Age }_{\mathrm{j}} \\
+\beta_{6} \text { Gender }_{\mathrm{j}}+\beta_{7} \text { Parental Assessment }_{\mathrm{ij}}+u_{0 \mathrm{j}}+\epsilon_{i j}
\end{array}
\end{aligned}
$$

where Postconcussion Symptoms Score $_{i j}$ is the HBI score of the $\mathrm{j}^{\text {th }}$ adolescent on session $\mathrm{i}$, the $\beta \mathrm{s}$ are the fixed effect coefficients, $u_{0 \mathrm{j}}$ is the random intercept for the $\mathrm{j}^{\text {th }}$ participant, and $\epsilon_{i j}$ is the error term.

This conservative statistical analysis is often preferred to traditional analyses such as ANOVAs (Boisgontier \& Cheval, 2016) because it avoids information loss due to averaging over participants (Judd, 
Westfall, \& Kenny, 2012) and is less vulnerable to type 1 errors (Baayen, Davidson, \& Bates, 2008). The time postconcussion (1, 3, 6 months), age, gender, and the parental assessment of the symptoms were included in the linear mixed model and the continuous variables were scaled and centered on zero. An estimate of the effect size was reported using the marginal pseudo $\mathrm{R}^{2}$.

\section{RESULTS}

Results of the linear mixed model (effect size $=.572$ ) showed a significant effect of physical activity $(b=-4.842, \mathrm{SE}=5.110, p=.010)$ on postconcussion symptoms (Table 1$)$. For every increase in physical activity by 1 standard deviation ( $S D=.76)$, postconcussion symptoms decreased by 4.842 units (Figure 1 ). This effect was observed while controlling for time postconcussion $(b=1.919, \mathrm{SE}=1.340, p=.193)$, age $(b=8.279, S E=4.142, p=.071)$, sex $(b=-10.881, S E=6.442, p=.121)$, and the parental assessment of the symptoms $(b=.813, S E=1.408, p=.578)$. A model including an interaction between physical activity and time postconcussion was also tested but the interaction effect was not significant $(b=-.601, S E=$ $1.375, p=.673$ ) and the quality of this model was lower as indicated by a higher Akaike Information Criterion (127.7 vs.125.9).

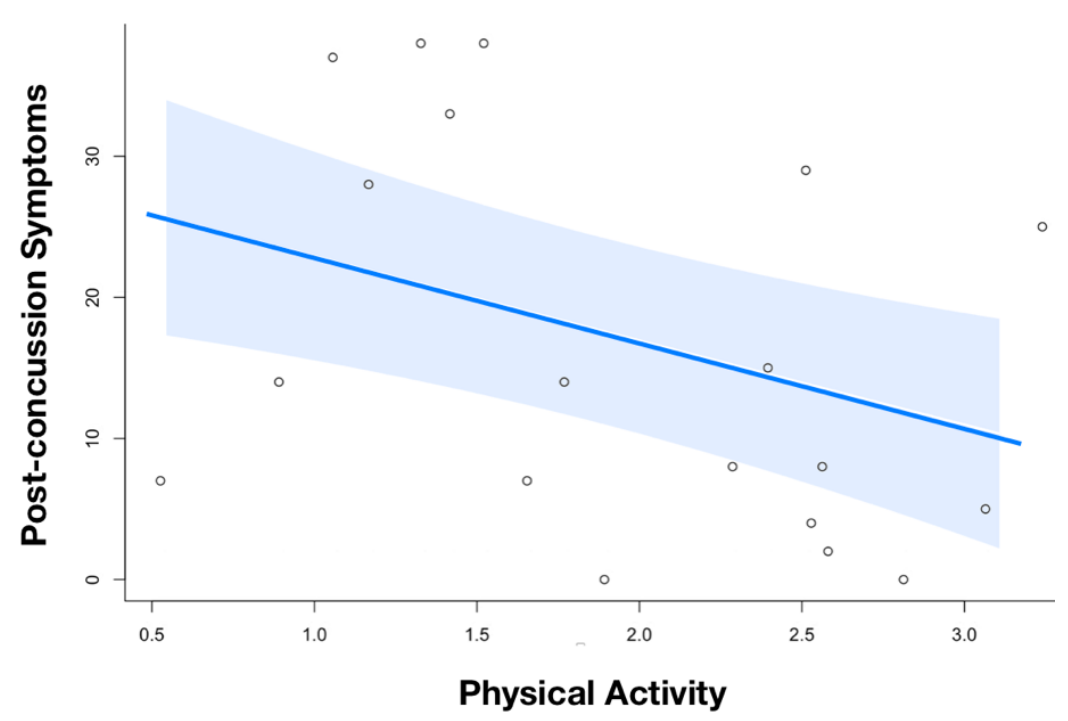

Figure 1. Fixed effect and the 95\% confidence interval of physical activity (Physical Activity Questionnaire for Adolescents score) on postconcussion symptoms (Health and Behavior Inventory postconcussion score) as estimated by the linear mixed model. This effect was significant irrespective of age, gender, parental health, and time postconcussion (1, 3, and 6 months). The scatter plot illustrates the raw data for all participants at the 3 postconcussion assessments.

\section{DISCUSSION}

These findings suggest that the engagement in daily-life physical activity reduces symptoms in an adolescent concussion population. In line with current guidelines (McCrory et al., 2017) and based on these findings, individuals should resume daily life occupations involving physical activity after a short rest period. This may include resumption of daily-life physical activity such as physical education, sports, or games during spare time.

In our study, physical activity was not conducted within a rehabilitation program. Instead, individuals re-engaged in normal daily life activities such as playing with friends, sports, and school-based programs. Our sample was comprised of individuals who sustained concussion from sport-related events, indicating individuals' participation in physical activity as part of a normal routine of everyday life. In this way, participants re-engaged in meaningful activities (e.g., physical activities) after concussion. Thus, preinjury daily life physical activities appear to promote postconcussion recovery in adolescents. 


\begin{tabular}{|c|c|c|c|c|}
\hline Fixed Effects & b (95Cl) & SE & $p$ & \\
\hline Intercept & $19.73(10.98 ; 28.47)$ & 4.46 & $<.001$ & $* * *$ \\
\hline Physical activity & $-4.84(-7.62 ;-2.05)$ & 1.42 & .010 & $*$ \\
\hline Time postconcussion & $1.91(-.70 ; 4.54)$ & 1.34 & .193 & \\
\hline Age & $8.27(.15 ; 16)$ & 4.14 & .071 & \\
\hline Gender & $-10.88(-23.50 ; 1.74)$ & 6.44 & 121 & \\
\hline Parental assessment & $.81(-1.94 ; 3.57)$ & 11.40 & .578 & \\
\hline Random Effect & $\sigma^{2}$ & & & \\
\hline \multicolumn{5}{|l|}{ Participant } \\
\hline Intercept & 84.919 & & & \\
\hline Residual & 5.747 & & & \\
\hline Akaike Information Criterion & & 125.9 & & \\
\hline Pseudo $\mathrm{R}^{2}$ & & .572 & & \\
\hline
\end{tabular}

Table 1. Estimated effects on the Health and Behavior Inventory score $\left({ }^{* * *} p<.001,{ }^{*} p<.05,95 \mathrm{Cl}\right.$ $=95 \%$ confidence interval)

It is not clear the mechanism of why this resolution of symptoms occurs with physical activity. It is possible that physical activity directly promotes neurological recovery in an adolescent concussion population (Schmidt, Rubino, Boyd, \& Virji-Babul, 2018). Alternatively, individuals who re-integrate into validated, meaningful life activities, including physical activities, experience minimal depressive symptoms, which in turn promote a positive recovery framework. The Activity Intolerance Cascade theorizes that individuals who do not re-engage in occupation will further self-limit engagement (DiFazio, Silverberg, Kirkwood, Bernier, \& Iverson, 2016). Lastly, the resolution of symptoms after engagement in daily life physical activity may be due to participation and validation within established social networks (school, sports teams), which in turn provides intrinsic motivation for recovery (Stålnacke, 2007). For the latter two postulations, individuals may have less vigilance on symptoms, and a greater focus on returning to meaningful occupations, social networks, and roles.

Further research is needed to understand the underlying reason as to why daily life physical activity is beneficial for symptom resolution after concussion, and whether this rationale could be applied to non-physical occupations. Additionally, research is needed to explore if this same benefit is found in other populations (e.g., younger children, adults).

These findings have important implications for occupational therapists who provide rehabilitation for adolescents with concussion. Based on this evidence, occupational therapists should promote reengagement in daily life physical activity occupations to enhance concussion recovery. An occupationbased approach would facilitate effective concussion management, focusing on enabling clients to engage in meaningful physically active occupations within their specific contexts (Townsend \& Polatajko, 2013). 


\section{CONCLUSION}

Engagement in daily-life physical activity may promote concussion recovery as demonstrated by a reduction in symptoms. These findings highlight the need for further research and individualized, clientcentered, occupation-based approaches in concussion management, encouraging the involvement of occupational therapists in evidence-based rehabilitation and education.

\section{Author contributions}

JS collected the data. MPB, JS designed the manuscript. MPB analyzed the data. MPB, JS drafted the manuscript. All authors contributed to the improvement of the manuscript.

\section{References}

Ayr, L. K., Yeates, K. O., Taylor, H. G., \& Browne, M. (2009). Dimensions of postconcussive symptoms in children with mild traumatic brain injuries. Journal of the International Neuropsychological Society, 15(1), 19-30. https://doi.org/10.1017/S1355617708090188

Baayen, R. H., Davidson, D. J., \& Bates, D. M. (2008). Mixed-effects modeling with crossed random effects for subjects and items. Journal of Memory and Language, 59(4), 390-412. https://doi.org/10.1016/j.jml.2007.12.005

Barlow, K. M. (2016). Postconcussion syndrome: A review. Journal of Child Neurology, 31(1), 57-67. https://doi.org/10.1177/0883073814543305

Barlow, K. M., Crawford, S., Stevenson, A., Sandhu, S. S., Belanger, F., \& Dewey, D. (2010). Epidemiology of postconcussion syndrome in pediatric mild traumatic brain injury. Pediatrics, 126(2), 374-381. https://doi.org/10.1542/peds.2009-0925

Billinger, S. A., Arena, R., Bernhardt, J., Eng, J. J., Franklin, B. A., Johnson, C. M., ... Tang, A. (2014). Physical Activity and Exercise Recommendations for Stroke Survivors. Stroke, 15(1), 19-30. https://doi.org/10.1161/str.0000000000000022

Boisgontier, M. P., \& Cheval, B. (2016). The anova to mixed model transition. Neuroscience and Biobehavioral Reviews, 68, 1004-1005. https://doi.org/10.1016/j.neubiorev.2016.05.034

Chrisman, S. P. D., Whitlock, K. B., Somers, E., Burton, M. S., Herring, S. A., Rowhani-Rahbar, A., \& Rivara, F. P. (2017). Pilot study of the Sub-Symptom Threshold Exercise Program (SSTEP) for persistent concussion symptoms in youth. NeuroRehabilitation, 40(4), 493-499. https://doi.org/10.3233/NRE161436

Cotman, C. W., Berchtold, N. C., \& Christie, L. A. (2007). Exercise builds brain health: key roles of growth factor cascades and inflammation. Trends in Neurosciences, 30(9), 464-472. https://doi.org/10.1016/j.tins.2007.06.011

DiFazio, M., Silverberg, N. D., Kirkwood, M. W., Bernier, R., \& Iverson, G. L. (2016). Prolonged Activity Restriction After Concussion: Are We Worsening Outcomes? Clinical Pediatrics, 55(5), 443-451. https://doi.org/10.1177/0009922815589914

Gagnon, I., Galli, C., Friedman, D., Grilli, L., \& Iverson, G. L. (2009). Active rehabilitation for children who are slow to recover following sport-related concussion. Brain Injury, 23(12), 956-964. 
https://doi.org/10.3109/02699050903373477

Gagnon, I., Grilli, L., Friedman, D., \& Iverson, G. L. (2016). A pilot study of active rehabilitation for adolescents who are slow to recover from sport-related concussion. Scandinavian Journal of Medicine and Science in Sports, 26(3), 299-306. https://doi.org/10.1111/sms.12441

Grool, A. M., Aglipay, M., Momoli, F., Meehan, W. P., Freedman, S. B., Yeates, K. O., ... Zemek, R. (2016). Association between early participation in physical activity following acute concussion and persistent postconcussive symptoms in children and adolescents. JAMA - Journal of the American Medical Association, 316(23), 2504-2514. https://doi.org/10.1001/jama.2016.17396

Hajek, C. A., Yeates, K. O., Taylor, H. G., Bangert, B., Dietrich, A., Nuss, K. E., ... Wright, M. (2011). Agreement between parents and children on ratings of post-concussive symptoms following mild traumatic brain injury. Child Neuropsychology. 17(1), 17-33. https://doi.org/10.1080/09297049.2010.495058

Hugentobler, J. A., Quatman-Yates, C., Evanson, N. K., Paulson, A., Chicoine, C., Backeljauw, B., ... Kurowski, B. G. (2019). Active Rehabilitation After Childhood and Adolescent Mild Traumatic Brain Injury: a Narrative Review and Clinical Practice Implications. Current Physical Medicine and Rehabilitation Reports, 7(1), 15-22. https://doi.org/10.1007/s40141-019-0207-3

Imhoff, S., Fait, P., Carrier-Toutant, F., \& Boulard, G. (2016). Efficiency of an Active Rehabilitation Intervention in a Slow-to-Recover Paediatric Population following Mild Traumatic Brain Injury: A Pilot Study. Journal of Sports Medicine. https://doi.org/10.1155/2016/5127374

Iverson, G. L. (2005). Outcome from mild traumatic brain injury. Current Opinion in Psychiatry, 18(3), 301-317. https://doi.org/10.1097/01.yco.0000165601.29047.ae

Judd, C. M., Westfall, J., \& Kenny, D. A. (2012). Treating stimuli as a random factor in social psychology: A new and comprehensive solution to a pervasive but largely ignored problem. Journal of Personality and Social Psychology, 103(1), 54-69. https://doi.org/10.1037/a0028347

Kowalski, K. C., Crocker, P. R. E., \& Kowalski, N. P. (1997). Convergent validity of the Physical Activity Questionnaire for Adolescents. Pediatric Exercise Science, 9(4), 342-352. https://doi.org/10.1123/pes.9.4.342

Kurowski, B. G., Hugentobler, J., Quatman-Yates, C., Taylor, J., Gubanich, P. J., Altaye, M., \& Wade, S. L. (2017). Aerobic exercise for adolescents with prolonged symptoms after mild traumatic brain injury: An exploratory randomized clinical trial. Journal of Head Trauma Rehabilitation, 32(2), 7989. https://doi.org/10.1097/HTR.0000000000000238

Lal, A., Kolakowsky-Hayner, S. A., Ghajar, J., \& Balamane, M. (2018). The Effect of Physical Exercise After a Concussion: A Systematic Review and Meta-analysis. American Journal of Sports Medicine, 46(3), 743-752. https://doi.org/10.1177/0363546517706137

Larson, E. B., Wang, L., Bowen, J. D., McCormick, W. C., Teri, L., Crane, P., \& Kukull, W. (2006). Exercise is associated with reduced risk for incident dementia among persons 65 years of age and older. Annals of Internal Medicine, 144(2), 73-81. https://doi.org/10.7326/0003-4819-144-2-20060117000004

Mak, M. K., Wong-Yu, I. S., Shen, X., \& Chung, C. L. (2017). Long-term effects of exercise and physical therapy in people with Parkinson disease. Nature Reviews Neurology, 13(11), 689-703. https://doi.org/10.1038/nrneurol.2017.128

Mannix, R., O’Brien, M. J., \& Meehan, W. P. (2013). The epidemiology of outpatient visits for minor head 
injury: 2005 to 2009. Neurosurgery, 73(1), 129-134.

https://doi.org/10.1227/01.neu.0000429846.14579.41

McCrory, P., Meeuwisse, W., Dvořák, J., Aubry, M., Bailes, J., Broglio, S., ... Vos, P. E. (2017). Consensus statement on concussion in sport-the 5 th international conference on concussion in sport held in Berlin, October 2016. British Journal of Sports Medicine, 51(11), 838. https://doi.org/10.1136/bjsports-2017-097699

Rajabali, F., Turcotte, K., Pike, I., \& Babul, S. (2016). The burden of concussion among children and youth in British Columbia (update). Vancouver, BC: BC Injury Research and Prevention Unit, Child Health BC.

Schmidt, J., Rubino, C., Boyd, L. A., \& Virji-Babul, N. (2018). The role of physical activity in recovery from concussion in youth: A neuroscience perspective. Journal of Neurologic Physical Therapy, 42(3), 155. https://doi.org/10.1097/NPT.0000000000000226

Silverberg, N. D., \& Iverson, G. L. (2013). Is Rest After Concussion “The Best Medicine?” Journal of Head Trauma Rehabilitation, 28(4), 250-259. https://doi.org/10.1097/htr.0b013e31825ad658

Stålnacke, B. M. (2007). Community integration, social support and life satisfaction in relation to symptoms 3 years after mild traumatic brain injury. Brain Injury, 21(9), 933-942. https://doi.org/10.1080/02699050701553189

Sveen, U., Søberg, H. L., \& Østensjø, S. (2016). Biographical disruption, adjustment and reconstruction of everyday occupations and work participation after mild traumatic brain injury. A focus group study. Disability and Rehabilitation, 38(23), 2296-2304. https://doi.org/10.3109/09638288.2015.1129445

Townsend, E. A., \& Polatajko, H. J. (2013). Enabling occupation II: Advancing an occupational therapy vision for health, well-being, and justice through occupation (2nd ed.). Ottawa (ON): Canadian Association of Occupational Therapists Publications ACE.

Valovich McLeod, T. C., Wagner, A. J., \& Bacon, C. E. W. (2017). Lived Experiences of Adolescent Athletes Following Sport-Related Concussion. Orthopaedic Journal of Sports Medicine, 5(12). https://doi.org/10.1177/2325967117745033

Yeates, K. O., Fay, T. B., Taylor, H. G., Bangert, B., Dietrich, A., Nuss, K. E., ... Wright, M. (2010). Cognitive reserve as a moderator of postconcussive symptoms in children with complicated and uncomplicated mild traumatic brain injury. Journal of the International Neuropsychological Society, 16(1), 94-105. https://doi.org/10.1017/S1355617709991007 